\title{
Enhancing PV Inverter Reliability With Battery System Control Strategy
}

\author{
Ariya Sangwongwanich, Georg Angenendt, Sebastian Zurmühlen, Yongheng Yang, Dezso Sera, \\ Dirk Uwe Sauer, and Frede Blaabjerg
}

\begin{abstract}
The increasing integration of Photovoltaic (PV) and Battery Energy Storage Systems (PV-BESS) adds more power control flexibility of the PV systems. This offers an opportunity to improve the PV inverter reliability, where the loading of the $\mathrm{PV}$ inverter can be modified through the operation of the battery system (e.g., charge/discharge). In that case, the control strategy of battery systems will affect the PV inverter loading and thereby also the reliability. This paper investigates the potential solution to enhance the PV inverter reliability through the control of battery system, where three self-consumption control strategies are considered. The impact of the battery system control strategies on the $\mathrm{PV}$ inverter reliability is analyzed with the mission profile of a $6-\mathrm{kW}$ PV-BESS installed in Germany. The evaluation results indicate that limiting the maximum charging power of the battery system has high potential to enhance the $\mathbf{P V}$ inverter reliability, where the damage of power devices in the inverter can be reduced by approximately $\mathbf{5 0 \%}$.
\end{abstract}

Index Terms - Battery, control strategy, lifetime, mission profile, PV inverters, reliability, self-consumption.

\section{INTRODUCTION}

$\mathrm{T}$ O further increase the penetration level of Photovoltaic (PV) systems, a significant reduction in the cost of PV energy is still demanded. It is recommended in [1] that the cost of PV energy should be reduced by a factor of around three in the near future (e.g., from $0.18 \mathrm{USD} / \mathrm{kWh}$ in 2016 to $0.05 \mathrm{USD} / \mathrm{kWh}$ by 2030 for residential PV systems in the US) to increase the competitiveness of PV systems. This is a challenging target, which requires improving PV systems in several aspects. Among those, the PV inverter reliability is one of the areas that should be enhanced [1]. From the field experience, the PV inverter is one of the most fragile parts in PV systems and it is responsible for a majority of unexpected failure events [2]. As a consequence, such an event results

Manuscript received May 1, 2018. This work was supported by Innovation Fund Denmark through the Advanced Power Electronic Technology and Tools (APETT) project.

A. Sangwongwanich, Y. Yang, D. Sera, and F. Blaabjerg are with the Department of Energy Technology, Aalborg University, DK-9220 Aalborg, Denmark(e-mail: ars@et.aau.dk; yoy@et.aau.dk; des@et.aau.dk; fbl@ et.aau.dk).

G. Angenendt, S. Zurmühlen, and D. U. Sauer are with the Institute for Power Electronics and Electrical Drives, Rheinisch-Westfälische Technische Hochschule (RWTH) Aachen University, Aachen 52062, Germany (e-mail: Georg.angenendt@isea.rwth-aachen.de; Sebastian.Zurmuehlen@isea.rwthaachen.de; DirkUwe.Sauer@isea.rwth-aachen.de).

Digital Object Identifier 10.24295/CPSSTPEA.2018.00009 in higher maintenance cost as well as PV energy yield losses, and eventually, increasing the cost of PV energy. Therefore, enhancing the reliability of PV inverters has high potential to bring down the cost of PV energy.

The reliability of PV inverters (and power electronics in general) is strongly affected by the system operating condition (also referred to as the mission profile) [3]. In that regard, the control strategy of PV systems inevitably affects the PV inverter reliability, as it changes the operating conditions. Nevertheless, the relationship increases the awareness of control for reliability. In the literature, many attempts have been made in recent years to enhance the PV inverter reliability. For instance, in [4], a control strategy to limit the maximum feed-in power of the PV inverter has been discussed, and its contribution to the inverter reliability improvement has been analyzed in [5]. Another control strategy to reduce the thermal loading fluctuation of PV inverters was proposed in [6], where the maximum power point tracking algorithm is modified during the fast change in the solar irradiance condition. In both control strategies, there is a trade-off between the improvement in the PV inverter reliability and the PV energy yield loss, since the $\mathrm{PV}$ power extraction is intentionally reduced (power curtailment) to alleviate the thermal loading of PV inverters. In some cases, the effectiveness of those control strategies is thus limited, considering the overall cost of energy [5].

Recently, the integration of PV and Battery Energy Storage Systems (PV-BESS) has become more economical-viable due to the declining cost of battery systems and the supportive policies [7]. For instance, in recent years, more than $40 \%$ of residential PV systems in Germany have been installed with battery systems, where self-consumption schemes are widely adopted [8], [9]. With the integration of battery systems, more control flexibilities of the PV system is enabled. In that case, the loading of PV inverters can be reduced by storing a certain amount of PV energy in the battery, instead of being curtailed, as it is illustrated in Fig. 1. This thus offers a possibility to enhance the PV inverter reliability without a loss of the total energy production. Hereby, the control strategies for battery systems are important to maintain the energy yield or the power flow, which affects the PV inverter loading and thus its reliability. Considering the PV self-consumption scheme, there are several battery system control strategies [10]-[13], whose impacts have also been investigated and compared for several aspects (e.g., battery lifetime, grid-relieving effect) in the literature [14]-[17]. However, the influence on the PV inverter reliability has not been explored yet. 


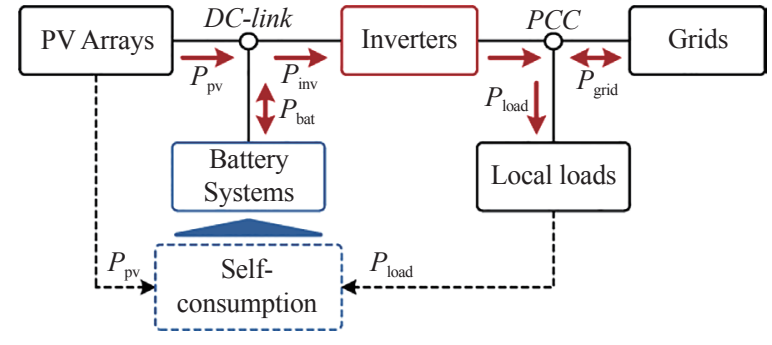

Fig. 1. Power flow of PV system with integrated battery system $\left(P_{\mathrm{pv}}: \mathrm{PV}\right.$ array output power, $P_{\text {bat }}$ : battery power, $P_{\text {inv }}: \mathrm{PV}$ inverter input power, $P_{\text {load }}$ : load consumption, and $P_{\text {grid }}$ : power exchanged with the grid).

In this paper, the impact of battery system control strategies on the PV inverter reliability is analyzed. The analysis is carried out on a 6-kW PV-BESS with a PV self-consumption scheme. The control strategies for battery systems are described in Section III, and the impact on the PV inverter loading is discussed in Section IV. Then, a reliability assessment of the PV inverter is carried out in Section V, where the mission profile of the PV-BESS installed in Germany is considered. Finally, concluding remarks are given in Section VI.

\section{System Description of PV-BESS}

In this paper, a single-phase PV-BESS is considered, as shown in Fig. 2, where the battery system is connected to the DC-link of the PV system, being a DC-coupled configuration. The system parameters are given in TABLE I.

\section{A. PV Arrays and Converter}

PV arrays are the main power source of the system. Since the PV array characteristic is strongly dependent on the environmental conditions (e.g., the solar irradiance and temperature), a Maximum Power Point Tracking (MPPT) operation is normally employed to maximize the PV energy yield. This is achieved through the control of the PV converter (e.g., the DC-DC converter), which regulates the PV array voltage at the Maximum Power Point (MPP), and the extracted PV power is then delivered to the DC-link [18].

\section{B. Battery and Converter}

For the DC-coupled configuration, the battery system is connected to the DC-link in parallel with the PV converter. Here, the battery system adds more power control flexibility, where the self-consumption control scheme can be implemented. The charging and discharging of the battery (i.e., bidirectional power flow) is achieved by controlling the battery converter (e.g., the bidirectional DC-DC converter). In this paper, the battery system parameters are designed according to the recommendation in [19], where the ratio between the battery capacity and the $\mathrm{PV}$ array rated power $(\mathrm{kWh} / \mathrm{kWp})$ is selected as 1:1.

\section{PVInverter}

The PV inverter is the interface between the DC-link and
TABLE I

Parameters of the Single-Phase PV-BESS (Fig. 2)

\begin{tabular}{lc}
\hline \hline PV array rated power & $6 \mathrm{~kW}$ \\
Battery capacity & $6 \mathrm{kWh}$ \\
Battery converter rated power & $3 \mathrm{~kW}$ \\
PV inverter rated power & $6 \mathrm{~kW}$ \\
DC-link capacitor & $C_{\mathrm{dc}}=1100 \mu \mathrm{F}$ \\
$L C$-filter & $L_{\text {inv }}=4.8 \mathrm{mH}, C_{f}=4.3 \mu \mathrm{F}$ \\
Switching frequency & Full-Bridge inverter: $f_{\text {inv }}=10 \mathrm{kHz}$ \\
DC-link voltage & $\nu^{*}{ }_{\text {dc }}=450 \mathrm{~V}$ \\
Grid voltage (RMS) & $V_{g}=230 \mathrm{~V}$ \\
Grid nominal frequency & $\omega_{0}=2 \pi \times 50 \mathrm{rad} / \mathrm{s}$ \\
\hline \hline
\end{tabular}

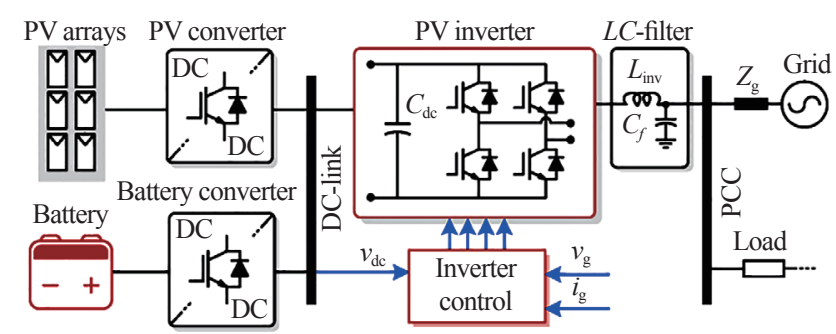

Fig. 2. System description of PV system with battery energy storage system (PV-BESS), where the battery system is connected to the DC-link.

the point of common coupling. The total power at the DClink, depending on the PV array output power and the battery power, should be delivered to the grid and/or load through the PV inverter. The DC-link voltage of the inverter is regulated to be constant through the control of the output AC current. Moreover, the injected current should be synchronized with the grid voltage, e.g., by means of phase-locked loops [20]. In this paper, a single-phase full-bridge PV inverter is used, as it is shown in Fig. 2. The power devices, whose reliability is considered, are Insulated-Gate Bipolar Transistor (IGBT) devices from [21]. Regarding the cooling system design, the heat sink is selected to limit the junction temperature of the power devices at $90^{\circ} \mathrm{C}$ when the inverter operates at the rated power (i.e., $6 \mathrm{~kW}$ ) and the ambient temperature is $50{ }^{\circ} \mathrm{C}$.

\section{Control Strategy of PV Self-Consumption}

The basic concept of the PV self-consumption is to locally consume the generated PV electricity within the household, instead of drawing the electricity from the grid to supply the loads. The Self-Consumption Rate (SCR) is normally defined as the ratio between the self-consumed energy Eself and the generated PV energy $E_{\mathrm{pv}}: \mathrm{SCR}=E_{\text {self }} / E_{\mathrm{pv}}$ [13]. Clearly, the higher the SCR is, the better the utilization of PV energy for local consumption will be. With battery systems, the surplus PV power during the day can be stored in the battery, and it will be used to supply the loads during nights. As a result, the SCR of the PV systems can be increased. Several battery system control strategies to realize the self-consumption operation are available in the literature. The operational principle of different control strategies will be discussed in the following, where the one-day PV power 


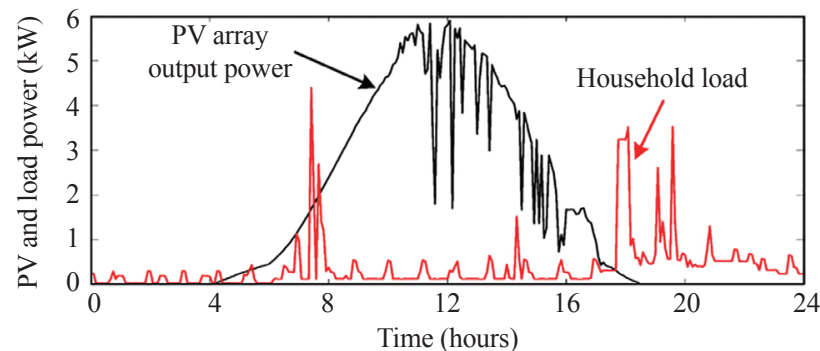

Fig. 3. Example of the PV power production and load profiles during a day.

and load profiles in Fig. 3 are considered.

\section{A. Maximizing Self-Consumption}

The most commonly-used battery system control strategy within the self-consumption scheme is the maximizing self-consumption method [13]. In this control strategy, the battery is charged as soon as the PV power production is higher than the load demand, as it is demonstrated by simulations in Fig. 4. By doing so, it can be ensured that the SCR of the PV-BESS is maximized, which is the advantage of this control strategy. However, this control strategy usually leads to a situation where the battery is fully charged before noon (especially during summer) [15], as it can be seen in Fig. 4(b) from the State of Charge (SOC) of the battery. This is undesirable from the grid integration perspective, since the battery system cannot contribute to the PV peak power reduction (e.g., the battery is fully charged before midday). Additionally, the early fully charged batteries will lead to a high average SOC during operation. This will accelerate the calendar aging of some types of batteries (i.e., lithium-ion batteries), which limits the battery lifetime [22].

\section{B. Delaying Charging Period}

To tackle the above issues, a control strategy that delays the charging period of the battery system has been discussed in [12]. In this control strategy, the battery will not be charged immediately when the surplus PV power becomes positive. In contrast, the battery will be charged after a certain time period in a way to shift the charging period from the early morning to midday. An operational example of the delaying charging period control strategy is shown in Fig. 5, where the battery is allowed to be charged after 9:00. In this case, the battery is fully charged around 12:00.

Compared with the maximizing self-consumption control strategy in Fig. 4, the time duration where the battery SOC is kept at $100 \%$ is reduced with this control strategy. Thus, the average SOC of the battery is effectively reduced. As a consequence, the lifetime of the battery can be improved and at the same time a certain amount of PV peak power injected into the grid is reduced. However, this control strategy may reduce the SCR in the case of a low solar irradiance conditions (e.g., during winter period), where the battery may not be fully charged by the end of the day (e.g., less load during night can be supplied by the PV energy). In that case, the PV

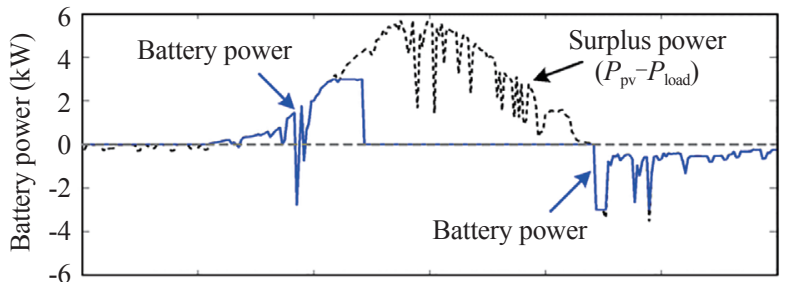

(a)

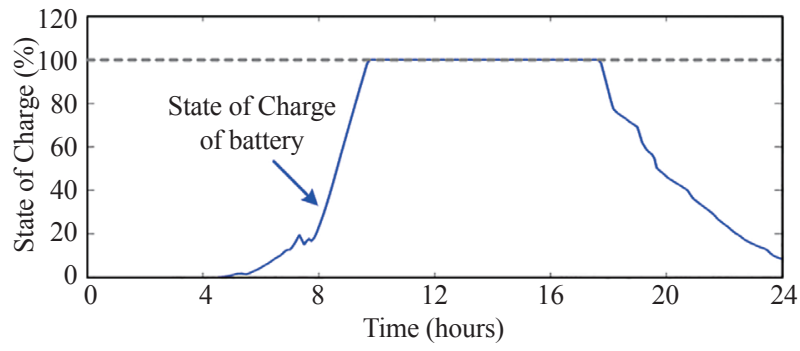

(b)

Fig. 4. Operation principle of the PV-BESS with the maximizing self-consumption control strategy: (a) battery power and (b) State of Charge of the battery.

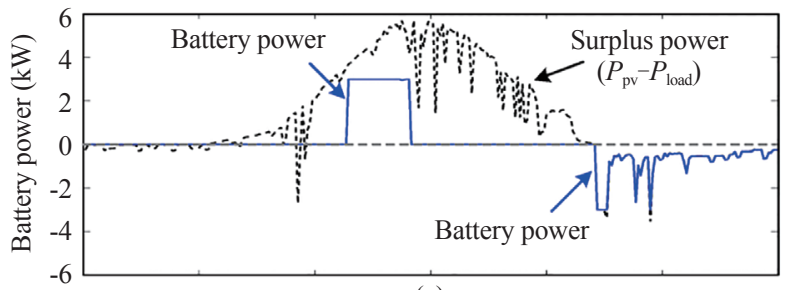

(a)

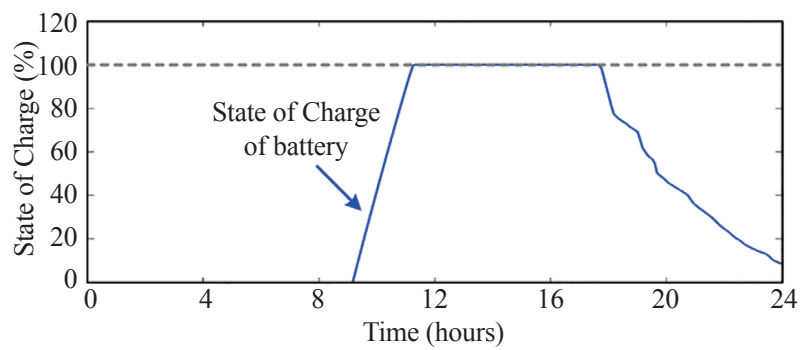

(b)

Fig. 5. Operation principle of the PV-BESS with the delaying charging period control strategy: (a) battery power and (b) State of Charge of the battery.

energy is not fully utilized for local consumption.

\section{Limiting Charging Power}

Limiting the charging power of the battery is another possible solution to avoid the battery to be fully charged early in the day. In this control strategy, the maximum battery charging power is limited to a certain value [11]. When the surplus PV power is higher than the charging power limit, the battery will be charged with a constant power corresponding to the maximum power limit, while the rest of the surplus PV power will be delivered to the grid. The operation of this control strategy is demonstrated in Fig. 6, where the maximum charging power of the battery is kept at $30 \%$ of the battery converter power rating (i.e., the maximum 


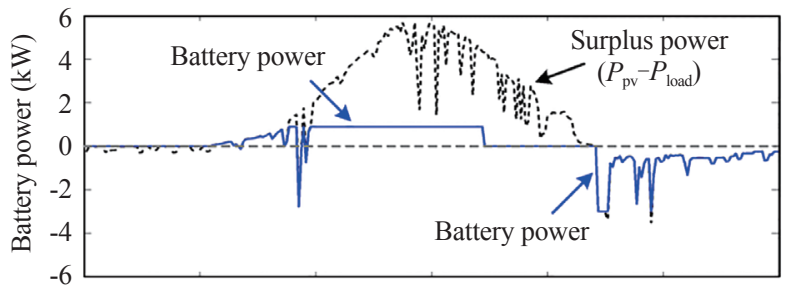

(a)

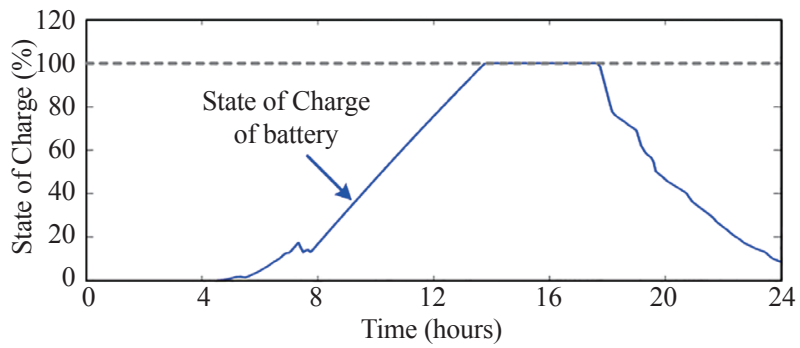

(b)

Fig. 6. Operation principle of the PV-BESS with the limiting charging power control strategy: (a) battery power and (b) State of Charge of the battery.

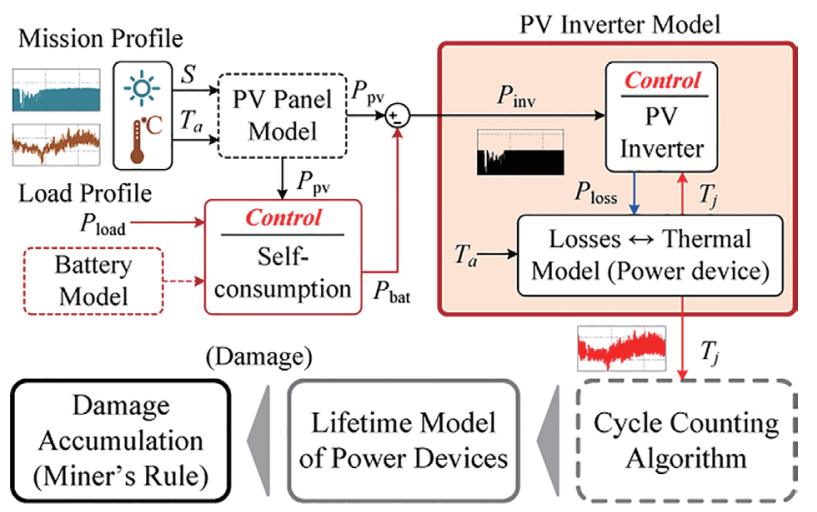

Fig. 7. Loading determination and reliability evaluation process of $\mathrm{PV}$ inverters with battery systems under with self-consumption.

charging power is $900 \mathrm{~W}$ ). As a result, the battery charging time is prolonged, where the battery is fully charged around 14:00.

The limiting charging power control strategy can effectively reduce the average SOC of the battery, as it can be seen from the battery SOC in Fig. 6(b). However, its contribution to the grid-relieving is limited, since a part of the surplus power is injected to the grid due to the limited battery charging power. Moreover, it also shares the same drawback with the delaying charging period method, where the SCR may be reduced during a low irradiance day.

\section{Impact of Battery System Control Strategy on PV INVERTER LOADING}

In this section, the impact of battery system control strategies on the PV inverter loading is analyzed. There are several quantities to map the PV inverter loading: 1) the input power of PV inverters, 2) the thermal stress of the power devices, and 3 ) the damage of the power devices, which can be

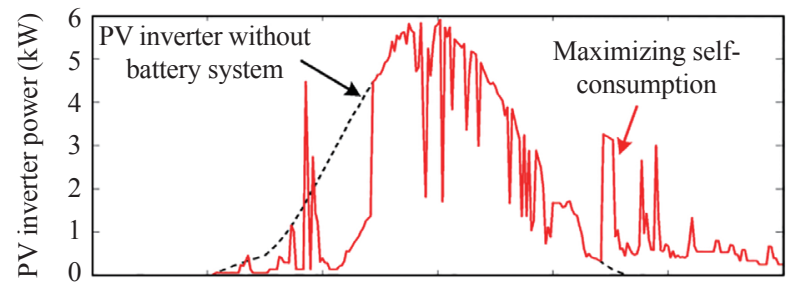

(a)

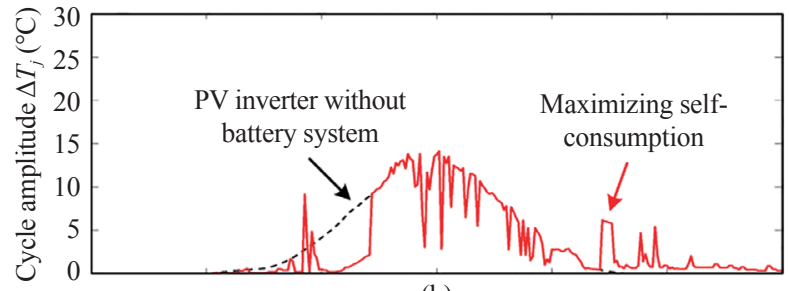

(b)

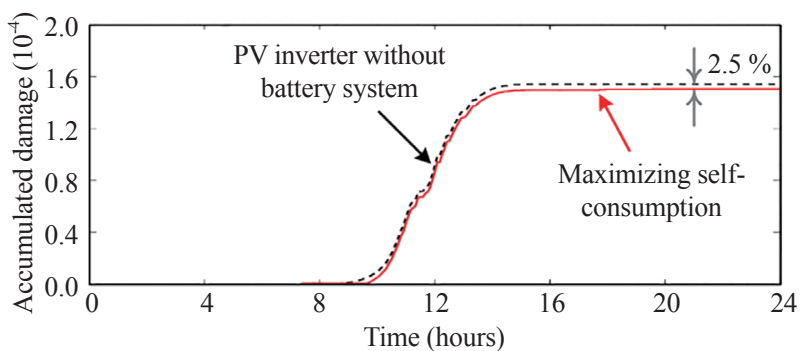

(c)

Fig. 8. Loading of the PV inverter with the maximizing self-consumption control strategy: (a) PV inverter power $P_{\mathrm{pv}}$, (b) the thermal cycle amplitude of the power device $\Delta T_{j}$, and (c) the damage accumulation of the power device.

obtained following the procedure in Fig. 7. This procedure will be explained in details.

\section{A. Input Power of PV Inverters}

The input power of the PV inverter $P_{\text {inv }}$ can be used to represent the system-level loading of the PV inverter. For the PV-BESS, the input power of the PV inverter $P_{\text {inv }}$ can be obtained by subtracting the PV array output power $P_{\mathrm{pv}}$ with the battery power $P_{\text {bat }}$. Therefore, the battery system control strategy (discussed in Section III) will determine the battery power, as it is shown in Fig. 7.

Here, the impact of battery system control strategies on the input power of the PV inverters is demonstrated by using the one-day PV power and load profiles in Fig. 3. The input power of the PV inverter with the maximizing self-consumption control strategy is demonstrated in Fig. 8(a), where the battery power profile in Fig. 4(a) is used. It can be seen that the maximizing self-consumption control strategy can reduce the input power of the PV inverter during the early morning, which corresponds to the charging time period of the battery. However, the PV inverter will experience similar peak loading periods during noon as the case of PV inverters without battery system, since the batteries have been fully charged before noon and thus the PV peak-power cannot be stored.

On the other hand, the loading of PV inverters during the PV peak power generation period can be reduced with 


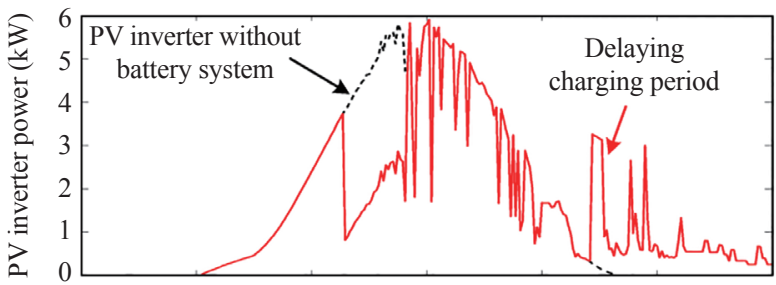

(a)

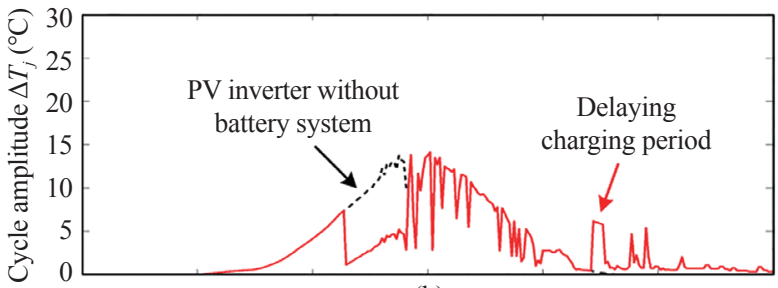

(b)

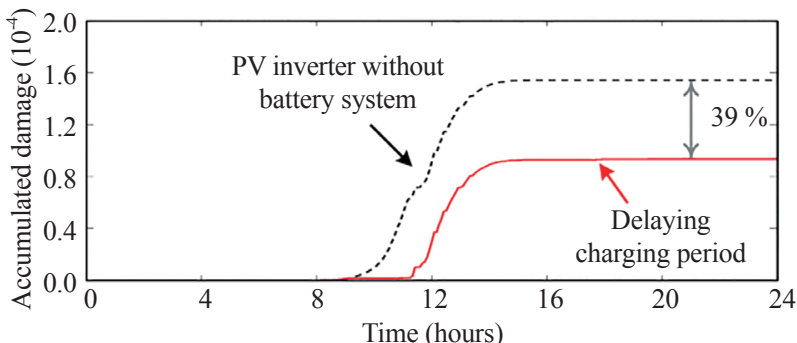

(c)

Fig. 9. Loading of the PV inverter with the delaying charging period control strategy: (a) PV inverter power $P_{\mathrm{pv}}$, (b) the thermal cycle amplitude of the power device $\Delta T_{j}$, and (c) the damage accumulation of the power device.

the delaying charging period control strategy, as it can be seen in Fig. 9(a). In this case, the PV inverter loading starts decreasing after 9:00, which is the time when the battery system starts the operation (i.e., Fig. 5(a)). Therefore, a certain amount of PV power during noon is stored in the battery, and thus the peak load of the PV inverter can be reduced to some extent.

Similarly, the limiting charging power control strategy contributes also to the peak load reduction of the PV inverters. The input power of the PV inverters under this control strategy is demonstrated in Fig. 10(a). It can be seen in Fig. 10(a) that the loading of the PV inverter is reduced with the power difference corresponding to the maximum charging power. In this case, the load reduction starts from early morning until afternoon, corresponding to the battery charging time period.

Notably, the input power of the PV inverter during night is similar for all battery control strategies, since they share the same discharging control strategy (e.g., discharging as soon as the surplus power becomes negative). In that case, the loading of PV inverters will be increased during nights, as the battery is discharged to supply the load through the PV inverter.

\section{B. Thermal Stress of Power Devices}

The thermal stress of power devices is another quantity that can be used to indirectly assess the reliability. Thus, the impact of battery system control strategies on the PV

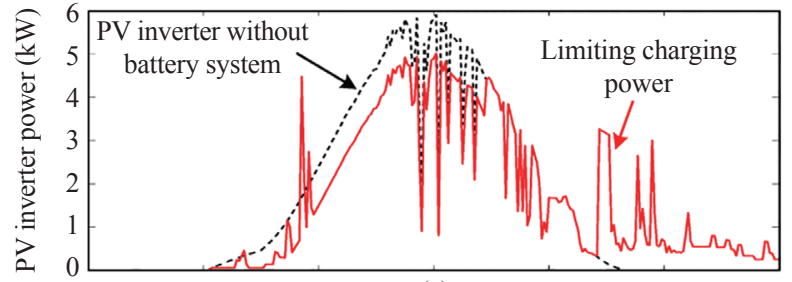

(a)

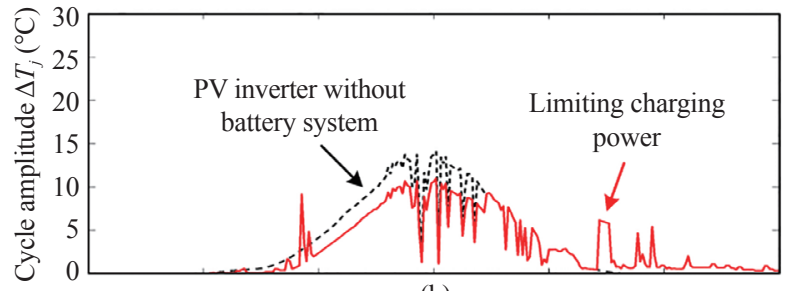

(b)

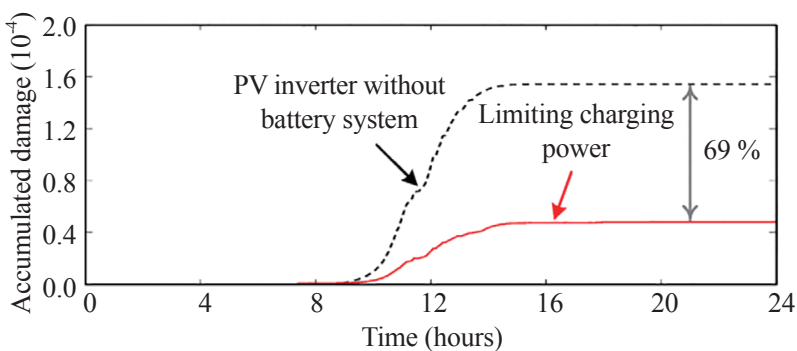

(c)

Fig. 10. Loading of PV the inverter with limiting charging power control strategy: (a) PV inverter power $P_{\mathrm{pv}}$, (b) the thermal cycle amplitude of the power device $\Delta T_{j}$, and (c) the damage accumulation of the power device.

inverter reliability can be analyzed considering the thermal stress of the power devices [23]. From the input power of the $\mathrm{PV}$ inverter, the thermal stress of the power devices can be obtained using the loss and thermal models of the power device, as it is shown in Fig. 7. Notably, the translation from the input power to the power loss and thermal stress is normally realized through a look-up table in order to handle long-term simulations (e.g., one-year mission profile). More details about the mission profile translation has been provided in [24]. For IGBT power devices, the cycle amplitude $\Delta T_{j}$ of the junction temperature is the main stress factor that induces wear-out failures after a number of cycles (e.g., resulting in bond-wire lift-off) [3].

The thermal stress of the power device under different battery system control strategies is determined by translating the input power of the PV inverter in Fig. 8(a), Fig. 9(a), and Fig. 10(a) into the junction temperature of the power device (e.g., the cycle amplitude) following Fig. 7. In general, the thermal stress of the power device has a similar tendency as the input power profile of the PV inverter. More specifically, the cycle amplitude of the power device decreases significantly in the early morning with the maximizing self-consumption control strategy, as it is shown in Fig. 8(b). In the case of the delaying charging period control strategy, the thermal stress of the power device starts decreasing after the battery system is activated (i.e., after 9:00), as it is shown in Fig. 9(b). For the limiting charging power control strategy, the thermal stress in the power device reduces from the early 
morning until the afternoon, covering the PV peak power generation period, as it is shown in Fig. 10(b).

\section{Damage Evaluation of Power Devices}

For power devices, one main wear-out failure mechanism is related to the thermal cycling, which can cause the bond-wire lift-off after a number of thermal cycles [25]. Therefore, a cycle counting algorithm such as the rainflow analysis needs to be applied to the thermal stress profile in order to obtain the thermal cycling information. Normally, it is assumed that the contribution of each thermal cycle to the failure, also referred to as damage, is accumulated linearly and independently during operation (i.e., using the Miner's rule) [3]. For instance, the accumulated damage in the power device during operation is calculated as

$$
A D=\sum_{i} \frac{n_{i}}{N_{f i}}
$$

where $A D$ is the accumulated damage of the power device. $n_{i}$ is the number of cycles for a certain thermal stress condition (e.g., the cycle amplitude $\Delta T_{j}$, the mean value $T_{j m}$, and the cycle period $\left.t_{o n}\right)$, which is obtained from the cycle counting algorithm. $N_{f i}$ is the number of cycles to failure at a certain stress condition, which can be calculated from the lifetime model of the power device as

$N_{f}=A \cdot\left(\Delta T_{j}\right)^{\alpha} \cdot(a r)^{\beta_{1} \Delta T_{j}+\beta_{0}} \cdot\left[\frac{C+\left(t_{o n}\right)^{\gamma}}{C+1}\right] \cdot \exp \left(\frac{E_{a}}{k_{b} \cdot T_{j m}}\right) \cdot f_{d}$

where the lifetime model parameters are given in TABLE II [25]. It is worth mentioning that this lifetime model is obtained through the accelerated testing where the power devices are subjected to the stress level higher than normal operation in order to obtain the test results in a reasonable time. This lifetime prediction (damage calculation) is based on the extrapolation of this model when the operating condition falls outside the testing conditions [3].

The accumulated damage $A D$ can be used as a quantitative reliability metric to compare the contribution of the operating condition (e.g., battery system control strategies) to the reliability of power devices. It indicates a proportion of the component lifetime that has been consumed during the operation. The operation with high accumulated damage indicates low reliability, resulting in a high failure rate, where the end of life of the power devices is reached when the damage is accumulated to unity (i.e., $A D=1$ after a few years of operation) [3].

The accumulated damage during one-day operation is obtained by considering the thermal stress in the power devices, and it is compared with the case of the PV inverter without battery system. It can be seen in Fig. 8(c) that the maximizing self-consumption control strategy has a limited contribution to the damage reduction of the power devices. On the other hand, the control strategy with a delaying charging period can reduce the damage of the power devices
TABLE II

Parameters of the Lifetime Model of an IGBT Module Used in the PV INVERTER [25]

\begin{tabular}{clc}
\hline \hline Parameter & Value & Experimental Condition \\
\hline$A$ & $3.4368 \times 10^{14}$ & \\
$\alpha$ & -4.923 & $64 \mathrm{~K} \leq \Delta T_{j} \leq 113 \mathrm{~K}$ \\
$\beta_{I}$ & $-9.012 \times 10^{-3}$ & \\
$\beta_{0}$ & 1.942 & $0.19 \leq a r \leq 0.42$ \\
$C$ & 1.434 & \\
$\gamma$ & -1.208 & $0.07 \mathrm{~s} \leq t_{\text {on }} \leq 63 \mathrm{~s}$ \\
$f_{d}$ & 0.6204 & $32.5^{\circ} \mathrm{C} \leq T_{j} \leq 122{ }^{\circ} \mathrm{C}$ \\
$E_{a}$ & $0.06606 \mathrm{eV}$ & \\
$k_{B}$ & $8.6173324 \times 10^{-5} \mathrm{eV} / \mathrm{K}$ & \\
\hline \hline
\end{tabular}

significantly, where the accumulated damage during oneday is reduced by $39 \%$ (compared to the case of the PV inverter without battery system), as it is shown in Fig. 9(c). Nevertheless, the battery system control strategy with a limited charging power is the most effective solution in terms of damage reduction, as it can be seen in Fig. 10(c). In that case, the accumulated damage during one-day is reduced by $69 \%$ (compared to the case of the PV inverter without battery system). This is mainly due to the reduced peak load of the PV inverter during noon, where the maximum cycle amplitude of the power device junction temperature is decreased and thereby the damage of power devices is reduced significantly.

\section{Reliability Assessment of PV Inverters With Self- Consumption Control Strategy}

The previous analysis during one-day operation suggests that the battery system control strategy can strongly affect the reliability of PV inverters. Nevertheless, the impact of the control strategy is also dependent on the mission profile of the PV system (e.g., solar irradiance and ambient temperature), which varies during the operation [23]. In this section, the reliability assessment of the PV inverter is carried out with a one-year mission profile of the PV-BESS in Germany. By doing so, the seasonal variations in the mission profile (e.g., during summer and winter) can be included in the analysis, and the long-term impact of the battery system control strategies on the PV inverter reliability is then examined.

\section{A. Mission Profile of PV-BESS}

For PV systems, the mission profile usually consists of the solar irradiance and the ambient temperature, as the PV array output power is mainly determined by the two parameters [24]. One-year solar irradiance and ambient temperature profiles recorded in Lindenberg, Germany are shown in Fig. 11 and used as a case study, where the annual PV energy yield is approximately $6600 \mathrm{kWh} /$ year. Due to a strong seasonal variation (e.g., between summer and winter) in the mission profile, it can be expected that the amount of surplus power during the day in the summer will be much higher than that in winter. In that case, the issues associated with the early 


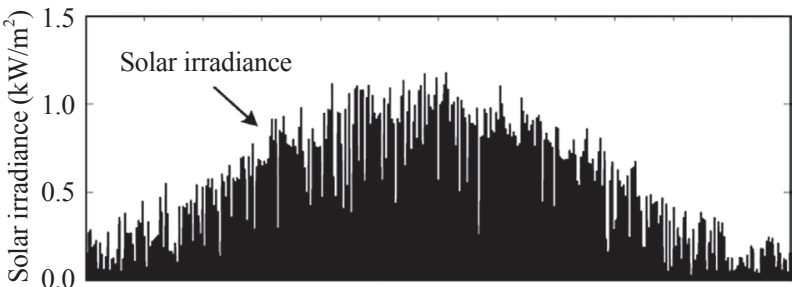

(a)

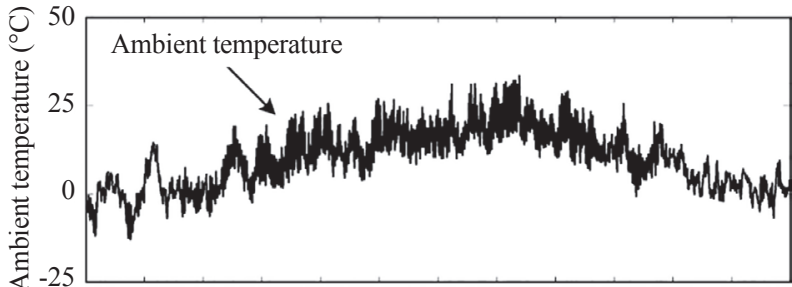

(b)

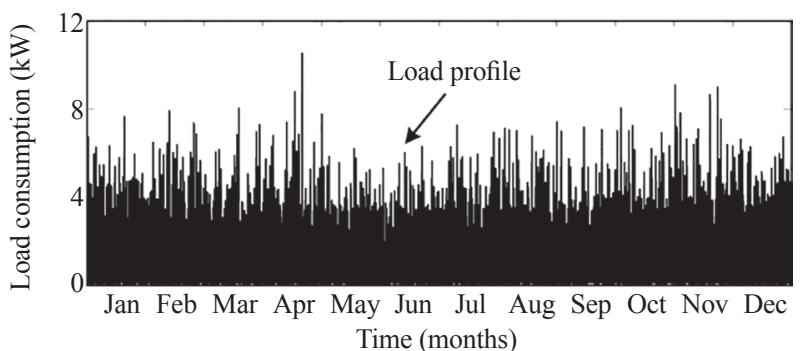

(c)

Fig. 11. One-year mission profile of the PV-BESS in Lindenberg, Germany with a sampling rate of 1 minute per sample: (a) solar irradiance, (b) ambient temperature, and (c) household load profile.

fully charged battery will be more pronounced in summer.

In addition to the solar irradiance and ambient temperature profiles, the household load profile also plays an important role in determining the battery system operation under the self-consumption scheme. Here, a one-year load profile of typical residential household shown in Fig. 11(c) is employed. This load profile is stochastically modified based on the measurement data to represent the dynamic behavior and variation in the household load [26]. The annual energy consumption is approximately $4800 \mathrm{kWh} /$ year, which represents an average 4-person household load. From the load and PV array output power profiles, the battery power can then be obtained according to the battery system control strategy.

\section{B. Description of the Case Study}

In the analysis, three case studies with different battery system control strategies are applied to the mission profile in Fig. 11. As discussed previously, the delaying charging period and limiting charging power control strategies may reduce the SCR during the day with low irradiance conditions. To minimize this drawback, the above two control strategies are not applied during the winter period (i.e., November-February), since the surplus energy during the day is already lower than the battery capacity. Instead, the control strategy similar to the maximizing self-consumption is applied to all cases during the winter period, as it is suggested in [14].
TABLE III

Accumulated Damage in the Power Device Under Different Battery System Control Strategies

\begin{tabular}{lc}
\hline \hline Control Strategy & Accumulated Damage (per year) \\
\hline Without battery system & $16.2 \times 10^{-3}$ \\
Maximizing self-consumption & $15.2 \times 10^{-3}$ \\
Delaying charging period & $9.75 \times 10^{-3}$ \\
Limiting charging power & $8.05 \times 10^{-3}$ \\
\hline \hline
\end{tabular}

Additionally, the start charging time and the maximum charging power are the parameters that strongly affect the battery system operation for the delaying charging period and the limiting charging power control strategies, respectively. In general, using a low charging power or large delaying charging period (e.g., start charging the battery after 10:00) will further benefit the PV inverter reliability, but decrease the SCR (e.g., during low solar irradiance days). In this case study, the battery with the delaying charging period control strategy is charged after 9:00, while the maximum charging power of the limiting charging power control strategy is selected as $30 \%$ of the rated power. These parameters are selected in a way to maintain an equal SCR for both control strategies (i.e., $2 \%$ lower SCR than that of the maximizing self-consumption control strategy). By doing so, the SCR of all control strategies are comparable (resulting in a similar energy yield), and the benefit in terms of reliability improvement of different control strategies can be benchmarked.

\section{Reliability Evaluation}

The reliability evaluation is carried out during one-year operation, where the battery system control strategies and the mission profile are considered. The $A D$ over one-year is used as a reliability metric to quantify the impact of battery system control strategies on the reliability of the PV inverter. The improvement in the PV inverter reliability can be analyzed by comparing the $A D$ of the PV inverter with battery system control strategies and the case without battery system.

The $A D$ of the power device in the PV inverter with different battery system control strategies is summarized in TABLE III. It can be seen that employing the maximizing self-consumption control strategy results in a comparable $A D$ as the case without battery system. Thus, its effectiveness in terms of PV inverter reliability enhancement is limited. On the other hand, the delaying charging period and limiting charging power control strategies can effectively improve the PV inverter reliability, where the $A D$ during operation is reduced significantly. It can be seen from the comparison in the $A D$ shown in Fig. 12 that the delaying charging period control strategy can reduce the $A D$ of the power device by approximately $40 \%$ compared to the case without batteries. Nevertheless, the limiting charging power control strategy is the most effective solution among the three control strategies in terms of the PV inverter reliability improvement, where more than $50 \%$ reduction in the $A D$ can be achieved. 


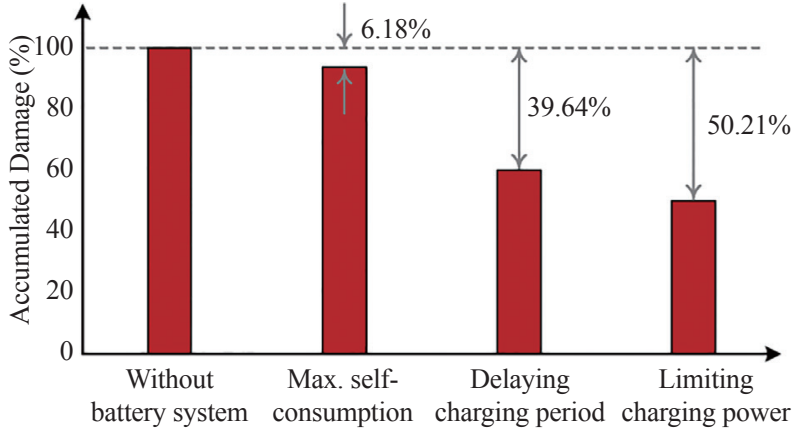

Fig. 12. Comparison of the accumulated damage of power device for different battery system control strategy over one year.

Accordingly, it can be seen that the delaying charging period and the limiting charging power control strategies are promising solutions to enhance the PV inverter reliability with a minimum reduction in the SCR (i.e., $2 \%$ lower than the maximizing self-consumption case).

\section{CONCLUSION}

In this paper, solutions to enhance the PV inverter reliability through the control of battery system were explored. Three different control strategies for self-consumption operation were discussed, and their impact on the PV inverter loading was investigated. The loading analysis indicates that the delaying charging period and limiting charging power control strategies can reduce the peak load of the PV inverter to some extent and thereby it has high potential for the reliability improvement. The reliability assessment has shown that the limiting charging power control strategy can effectively reduce the damage of power devices by $50 \%$ compared to the case of the PV inverter without a battery system. Therefore, it has the potential to enhance the reliability of the PV inverters, and thus maximize the benefit of the integration of battery systems in PV applications.

\section{REFERENCES}

[1] National Renewable Energy Laboratory, "On the path to sunshot: The role of advancements in solar photovoltaic efficiency, reliability, and costs,” Tech. Rep. No. NREL/TP-6A20-65872, 2016.

[2] Solar Bankability, "Technical risks in PV projects. report on technical risks in PV project development and PV plant operation," 2016.

[3] H. Huang and P. A. Mawby, "A lifetime estimation technique for voltage source inverters," IEEE Trans. Power Electron., vol. 28, no. 8, pp. 4113-4119, Aug. 2013.

[4] Y. Yang, H. Wang, F. Blaabjerg, and T. Kerekes, "A hybrid power control concept for PV inverters with reduced thermal loading," IEEE Trans. Power Electron., vol. 29, no. 12, pp. 6271-6275, Dec. 2014.

[5] Y. Yang, E. Koutroulis, A. Sangwongwanich, and F. Blaabjerg, "Pursuing photovoltaic cost-effectiveness: Absolute active power control offers hope in single-phase PV systems," IEEE Ind. App. Mag., vol. 23, no. 5, pp. 40-49, Sep. 2017.

[6] M. Andresen, G. Buticchi, and M. Liserre, "Thermal stress analysis and mppt optimization of photovoltaic systems," IEEE Trans. Ind. Electron., vol. 63, no. 8, pp. 4889-4898, Aug. 2016.

[7] T. Stetz, J. von Appen, F. Niedermeyer, G. Scheibner, R. Sikora, and
M. Braun, "Twilight of the grids: The impact of distributed solar on Germany's energy transition," IEEE Power Energy Mag., vol. 13, no. 2, pp. 50-61, Mar. 2015.

[8] IRENA, "Electricity storage and renewables: Costs and markets to 2030," 2017. [Online]. Available: http://www.irena.org/.

[9] J. Figgener, D. Haberschusz, K.-P. Kairies, O. Wessels, B. Tepe, M. Ebbert, R. Herzog, and D. U. Sauer, "Wissenschaftliches messund evaluierungsprogramm solarstromspeicher 2.0," Tech. Rep., 2017. [Online]. Available: http://www.speichermonitoring.de/.

[10] R. Luthander, J. Widn, D. Nilsson, and J. Palm, "Photovoltaic selfconsumption in buildings: A review," Applied Energy, vol. 142, pp. 8094, 2015.

[11] A. Zeh and R. Witzmann, "Operational strategies for battery storage systems in low-voltage distribution grids to limit the feed-in power of roof-mounted solar power systems," Energy Procedia, vol. 46, pp. 114-123, 2014.

[12] M. Schneider, P. Boras, H. Schaede, L. Quurck, and S. Rinderknecht, "Effects of operational strategies on performance and costs of electric energy storage systems," Energy Procedia, vol. 46, pp. 271-280, 2014.

[13] M. Resch, B. Ramadhani, J. Bühler, and A. Sumper, "Comparison of control strategies of residential PV storage systems," in Proc. of IRES, Mar. 2015, pp. 1-18.

[14] G. Angenendt, S. Zurmühlen, R. Mir-Montazeri, D. Magnor, and D. U. Sauer, "Enhancing battery lifetime in PV battery home storage system using forecast based operating strategies," Energy Procedia, vol. 99, pp. 80-88, 2016.

[15] J. Moshövel, K.-P. Kairies, D. Magnor, M. Leuthold, M. Bost, S. Gährs, E. Szczechowicz, M. Cramer, and D. U. Sauer, "Analysis of the maximal possible grid relief from PV-peak-power impacts by using storage systems for increased self-consumption," Applied Energy, vol. 137, pp. 567-575, 2015.

[16] M. Resch, J. Bühler, M. Klausen, and A. Sumper, "Impact of operation strategies of large scale battery systems on distribution grid planning in Germany," Renewable and Sustainable Energy Reviews, vol. 74, pp. 1042-1063, 2017.

[17] S. Zurmühlen, G. Angenendt, M. Heinrich, H. Axelsen, and D. U. Sauer, "Grid-relieving effects of PV battery energy storage systems with optimized operation strategies," in Proc. of EU PVSEC, Sep. 2017, pp. 1-5.

[18] D. U. Sauer, "Untersuchungen zum einsatz und entwicklung von simulationsmodellen fur die auslegung von photovoltaik-systemen,". Diploma thesis, TH Darmstadt, Apr. 1994.

[19] J. Weniger, T. Tjaden, and V. Quaschning, "Sizing of residential PV battery systems," in Proc. of IRES, 2013, pp. 78-87.

[20] F. Blaabjerg, R. Teodorescu, M. Liserre, and A.V. Timbus, "Overview of control and grid synchronization for distributed power generation systems," IEEE Trans. Ind. Electron., vol. 53, no. 5, pp. 1398-1409, Oct. 2006.

[21] SGP25N120, Infineon Technologies AG, 2009, rev. 2.5.

[22] D. Magnor, J. B. Gerschler, M. Ecker, P. Merk, and D. U. Sauer, "Concept of a battery aging model for lithium-ion batteries considering the lifetime dependency on the operation strategy," in Proc. of EU PVSEC, vol. 24, 2009.

[23] H. Wang, M. Liserre, F. Blaabjerg, P. de Place Rimmen, J. B. Jacobsen, T. Kvisgaard, and J. Landkildehus, "Transitioning to physics-of-failure as a reliability driver in power electronics," IEEE $J$. Emerg. Sel. Top. Power Electron., vol. 2, no. 1, pp. 97-114, Mar. 2014.

[24] Y. Yang, A. Sangwongwanich, and F. Blaabjerg, "Design for reliability of power electronics for grid-connected photovoltaic systems," CPSS Trans. Power Electron. Appl., vol. 1, no. 1, pp. 92-103, 2016.

[25] U. Scheuermann, R. Schmidt, and P. Newman, "Power cycling testing with different load pulse durations," in Proc. of PEMD 2014, Apr. 2014, pp. 1-6.

[26] M. Bost, B. Hirschl, and A. Aretz, "Effekte von eigenverbrauch und netzparität bei der photovoltaik-langfassung: Studie im auftrag von greenpeace energy. Berlin: Institut für ökologische wirtschaftsforschung (IÖW)," 2011. 


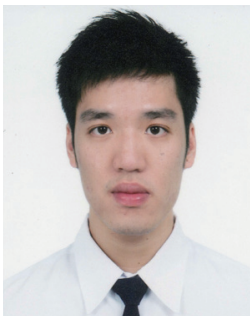

Ariya Sangwongwanich received the B.Eng. degree in electrical engineering from Chulalongkorn University, Thailand, in 2013, and the M.Sc. in energy engineering from Aalborg University, Denmark, in 2015, where he is currently working towards his Ph.D. degree.

He was a Visiting Researcher with RWTH Aachen University, Aachen, Germany from September to December 2017. His research interests include control of grid-connected converter, photovoltaic systems, reliability in power electronics and high-power multilevel converters.

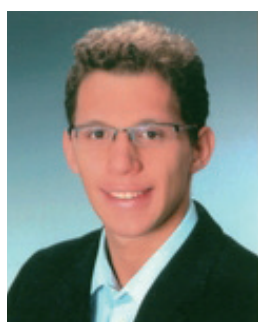

Georg Angenendt has a Master of Science degree in Business Administration and Engineering with specialization in Electrical Power Engineering from the RWTH Aachen. He has been working as a scientist and preparing for his $\mathrm{PhD}$ at the Institute of Power Electronics and Electrical Drives at RWTH Aachen University since January 2014 . He is working as a project manager and works on testing and modeling of lithium-ion batteries as well as on the optimization of PV home storage systems. Furthermore, he is researching in the field of domestic heat and power coupling and storage systems for DC-grids. His research results in numerous publications, which were presented at different conferences.

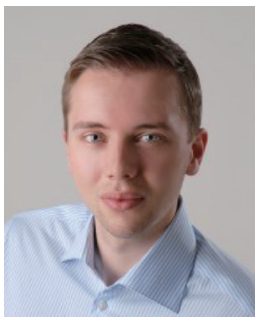

Sebastian Zurmühlen is a research associate, $\mathrm{PhD}$ student and head of section "Grid Integration and Storage System Analysis" at the Institute for Power Electronics and Electrical Drives at RWTH Aachen University. He holds a Master of Science degree in Business Administration and Engineering with specialization in Electrical Power Engineering from RWTH Aachen University. His work is focused on lithium-ion battery modelling and economics of PV home storage battery systems, grid-relieving effects of distributed storage systems as well as microgrid power systems for island applications.

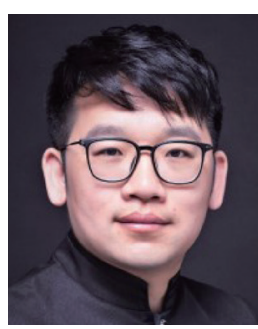

Yongheng Yang received the B.Eng. degree in electrical engineering and automation from Northwestern Polytechnical University, Shaanxi, China, in 2009 and the $\mathrm{Ph} . \mathrm{D}$. degree in electrical engineering from Aalborg University, Aalborg, Denmark, in 2014.

He was a postgraduate student at Southeast University, China, from 2009 to 2011. In 2013, he was a Visiting Scholar at Texas A\&M University, USA. Dr. Yang has been with the Department of Energy Technology, Aalborg University since 2014, first as a Postdoc researcher, then an Assistant Professor, and now an Associate Professor. He has been focusing on grid integration of renewable energies, in particular, photovoltaics, power electronic converter design, analysis and control, and reliability in power electronics.

Dr. Yang served as a Guest Associate Editor of IEEE Journal of Emerging and Selected Topics in Power Electronics and a Guest Editor of Applied Sciences. He is an Associate Editor of the CPSS Transactions on Power Electronics and Applications and an Editor of the Mathematical Problems in Engineering. Dr. Yang received the 2018 IET Premium Award for Best Paper in IET Renewable Power Generation.

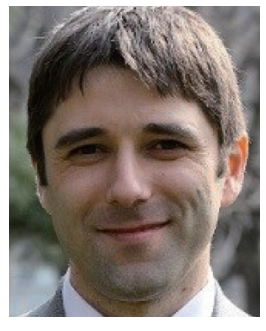

Dezso Sera received his B.Sc. and M.Sc. degrees in Electrical Engineering from the Technical University of Cluj, Romania in 2001 and 2002, respectively; MSc in Power Electronics and PhD on PV systems from Aalborg University, Denmark, Department of Energy Technology, where he currently works as Associate Professor.

Since 2009 he has been program leader of the Photovoltaic Systems Research Program (www. pv-systems.et.aau.dk) at the same dept. His research interests include modelling, characterization, diagnostics and maximum power point tracking (MPPT) of PV arrays, as well as power electronics and grid integration for PV systems.

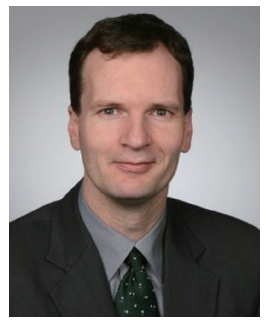

Dirk Uwe Sauer received a diploma degree in physics from University of Darmstadt and a PhD in electrochemistry from University of Ulm. From 1992 until 2003 he worked at the Fraunhofer Institute for Solar Energy Systems (ISE) in Freiburg, as scientist, project coordinator and head of the groups on Storage Systems and Off-grid Power Supply Systems. In 2003 he was appointed as a Junior professor for "Electrochemical Energy Conversion and Storage Systems" at RWTH Aachen University (2003) in the Faculty for Electrical Engineering and Information Technology and in 2009 he became Full Professor on the same subject also at RWTH Aachen University.

The research focus is on storage systems in hybrid and full electric vehicles, energy storage in grids with a high penetration of renewable energies including economic analysis, post-mortem analysis, ageing and lifetime prediction of batteries, modelling and diagnostics for batteries, impedance spectroscopy and impedance based modelling, and energy system analysis with regard to energy storage demand. The main technologies in focus are lithium-ion batteries, lead-acid batteries, supercaps, redox-flow batteries; concepts and consequences of a CO2-free energy supply. Prof. Sauer and Prof. Winter are the chairmen of the conference "Kraftwerk Batterie".

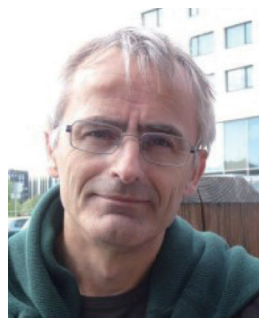

Frede Blaabjerg was with ABB-Scandia, Randers, Denmark, from 1987 to 1988. From 1988 to 1992 , he got the $\mathrm{PhD}$ degree in Electrical Engineering at Aalborg University in 1995. He became an Assistant Professor in 1992, an Associate Professor in 1996, and a Full Professor of power electronics and drives in 1998. From 2017 he became a Villum Investigator. $\mathrm{He}$ is honoris causa at University Politehnica Timisoara (UPT), Romania and Tallinn Technical University (TTU) in Estonia

His current research interests include power electronics and its applications such as in wind turbines, PV systems, reliability, harmonics and adjustable speed drives. He has published more than 500 journal papers in the fields of power electronics and its applications. He is the co-author of two monographs and editor of 7 books in power electronics and its applications.

He has received 26 IEEE Prize Paper Awards, the IEEE PELS Distinguished Service Award in 2009, the EPE-PEMC Council Award in 2010, the IEEE William E. Newell Power Electronics Award 2014 and the Villum Kann Rasmussen Research Award 2014. He was the Editor-in-Chief of the IEEE Transactions on Power Electronics from 2006 to 2012. He has been Distinguished Lecturer for the IEEE Power Electronics Society from 2005 to 2007 and for the IEEE Industry Applications Society from 2010 to 2011 as well as 2017 to 2018. In 2018 he is President Elect of IEEE Power Electronics Society.

He is nominated in 2014, 2015, 2016 and 2017 by Thomson Reuters to be between the most 250 cited researchers in Engineering in the world. 